\title{
SEGMENTAL THORACIC SPINAL ANAESTHESIA FOR CHOLECYSTECTOMY - A CLINICAL TRIAL
}

Ibemhal Heisnam, S. Thoibahenba, K. Upendra Singh, Ashikho Savio, Rita Rajkumari, Joyce

Tunglut, N. Charan Singh, Surmila Khoirom

1. Assistant Professor, Department of Anaesthesiology, JN Institute of Medical Sciences, Imphal.

2. Assistant Professor, Department of Anaesthesiology, JN Institute of Medical Sciences, Imphal.

3. Assistant Professor, Department of Anaesthesiology, JN Institute of Medical Sciences, Imphal.

4. Anaesthetist, Department of Anaesthesiology, MHS, Imphal.

5. Senior Resident, Department of Anaesthesiology, JN Institute of Medical Sciences, Imphal.

6. Senior Resident, Department of Anaesthesiology, JN Institute of Medical Sciences, Imphal.

7. Senior Resident, Department of Anaesthesiology, JN Institute of Medical Sciences, Imphal.

8. Senior Resident, Department of Anaesthesiology, JN Institute of Medical Sciences, Imphal.

\section{CORRESPONDING AUTHOR}

Dr. Ibemhal Heisnam,

Dept of Anaesthesiology,

JNIMS, Imphal - 795001

E-mail: dribemhal@gmail.com,

Ph: 00919856153557.

ABSTRACT: AIM OF STUDY: Cholecystectomy is generally performed under general anaesthesia but regional anaesthesia has been found beneficial, especially in patients with major medical problems. The objective of this study was to evaluate the effectiveness of segmental spinal anaesthesia in cholecystectomy so that it can be later used in patients when general anaesthesia is not feasible. MATERIALS AND METHODS: Twenty patients of ASA I and II of either sex undergoing elective cholecystectomy received a segmental spinal anaesthesia at $10^{\text {th }}$ thoracic interspace $\left(\mathrm{T}_{10}-\mathrm{T}_{11}\right)$ using $1.0 \mathrm{ml}$ bupivacaine heavy $\left(5 \mathrm{mgml}^{-1}\right)$ mixed with $0.5 \mathrm{ml}$ fentanyl $(25 \mu \mathrm{g})$. An epidural catheter was placed in the same space. Intraoperative haemodynamic parameters were monitored. Systemic drugs were administered if patients complained of pain, anxiety, hypotension, nausea or pruritus during or after surgery. RESULTS: The block was effective for surgery in all patients except two who required epidural top up. Four patients required midazolam for anxiety and five required mephenteramine for hypotension at two minutes after spinal injection, otherwise haemodynamics and respiratory parameters were within physiological limits. Twelve patients complained of mild pruritus around face and neck which did not require any treatment. Fifteen patients were able to ambulate after surgery. There was good surgeon and patients' satisfaction. CONCLUSION: Segmental Spinal Anaesthesia with bupivacaine and fentanyl could be a safe and effective alternative anaesthetic regime for cholecystectomy. However this technique requires great caution as the needle is inserted above the level of termination of the spinal cord and more studies with more number of cases are required befor advocating this technique.

KEY WORDS: Segmental thoracic spinal anaesthesia, cholecystectomy, bupivacaine, fentanyl.

INTRODUCTION: Gall stone disease is one of the most common aliment requiring surgical intervention. Cholecystectomy is usually performed under general anaesthesia, but, occasionally patients with major medical problems present significant challenges to the anaesthetist. General anaesthesia with opioids and neuromuscular blockers, as well as mechanical ventilation interferes with the respiratory system. The incidence of bronchial hyperactivity is increased in 
patients with asthma or COPD and regional anaesthesia has been found beneficial in managing such patients. Adopting appropriate anaesthetic techniques can tremendously influence the preoperative stress and produce a positive impact on the overall surgical outcome. This study has been conducted to evaluate the effectiveness and feasibility of segmental thoracic spinal anaesthesia in elective cholecystectomy.

MATERIALS AND METHODS: After obtaining approval of Institute Ethics Committee 20 patients aged between 18 and 75 years of either sex with ASA physical status I and II undergoing elective cholecystectomy were enrolled for the study. Informed written consents were taken from all the patients. Patients with active cholecystitis and any condition contraindicating elective surgery or spinal anaesthesia were excluded from the study. Patients were explained about the procedure and were assured that any pain, anxiety or discomfort during surgery would be treated effectively with intravenous medication, or if they preferred, conversion to general anaesthesia.

All the patients received oral alprazolam $0.5 \mathrm{mg}$ and ranitidine $150 \mathrm{mg}$ on the night prior to surgery. In the preoperative room patients were preloaded with Ringer lactate and premedicated with inj ondansetron $4 \mathrm{mg}$ intravenously. Monitoring includes NIBP, Pulse rate, peripheral oxygen saturation $\left(\mathrm{SpO}_{2}\right)$ and ECG.

The patients were placed in sitting position and under strict aseptic condition the $\mathrm{T}_{10^{-}}$ $\mathrm{T}_{11}$ epidural space was accessed using an $18 \mathrm{G}$ Tuohy needle and 'loss-of-resistance' to air method. An epidural catheter was threaded in the space and taped in place leaving $3 \mathrm{~cm}$ in epidural space. A test dose of $2 \mathrm{ml}$ lignocaine (2\%) with adrenaline $(1: 200,000)$ was injected through the epidural catheter. There was no sign of any sensory or motor block or significant vital sign change within 5 minutes after the test dose. Spinal anaesthesia was then performed with 25 G Quincke's needle in the same space $\left(\mathrm{T}_{10}-\mathrm{T}_{\mathrm{II}}\right)$. When correct placement was confirmed by the flow of clear CSF, $1 \mathrm{ml}$ bupivacaine heavy ( $\left.5 \mathrm{mgml}^{-1}\right)$ mixed with $0.5 \mathrm{ml}(25 \mu \mathrm{g})$ fentanyl was injected. The patients were then placed in the supine position and oxygen was given by face mask at the rate of 2 litres $\mathrm{min}^{-1}$.

Heart rate, blood pressure, and $\mathrm{SpO}_{2}$ were recorded every minute for the first 15 min and then every 5 minutes thereafter. Sensory block (upper and lower) was assessed by pin prick and recorded every 5 mins until the start of surgery and every 15 mins thereafter. Motor block was assessed using modified Bromage scale (0-able to lift extended legs; 1 - just able to flex knees, full ankle movement; 2-no knee movement, some ankle movement; 3- complete paralysis). Surgery was started after, the block reached $\mathrm{T}_{4}$ as assessed by pin prick.

During the procedure, patients were encouraged to report any discomfort, pain, nausea or pruritus and assured that general anaesthesia will be given if they wished. Pain was treated with inj. fentanyl $50 \mu \mathrm{g}$, anxiety with midazolam $2 \mathrm{mg}$ and hypotension with inj mephenteramine $3 \mathrm{mg}$, administered as iv boluses as when the systolic pressure drops more than $20 \%$ of the baseline during intra operative period. The epidural injections were to be administered in aliquots of $5 \mathrm{ml}$ isobaric bupivacaine $0.5 \%$, only if sensory block recedes below $\mathrm{T}_{6}$ dermatome and systemic drugs were ineffective in controlling pain. General anaesthesia were to be given if above measures fail to relived pain or if the surgeons faced technical difficulty for the surgery.

Operative times as well as intra operative events were recorded. Patients were monitored for one hour in the post operative ward and transferred to their respective ward 
after removal of epidural catheter. Before transferring, all the patients were asked about their satisfaction of the procedure and asked to grade as excellent, good or poor.

OBSERVATIONS AND RESULTS: The study included 20 patients, 4 males and 16 females with mean age of 41.7 $\pm 15: 97(S D)$; range (19-70) years, and mean weight of $53.35 \pm 9.22$ (SD); range (41-75) kgs. There were 15 ASA grade I and 5 ASA grade II patients. The duration of surgery was $60 \pm 14: 14$ (SD) minutes; range (45-90) minutes (Table I). None of the patient required conversion to general anaesthesia.

An effective sensory block, median level: upper $\mathrm{T}_{4}$ (range $\mathrm{T}_{3}-\mathrm{T}_{5}$ ); lower $\mathrm{L}_{3}\left(\mathrm{~L}_{1}-\mathrm{L}_{5}\right)$ developed within 15 minutes in every patient. Transient hypotension were recorded in 5 patients who were treated effectively with one dose of $3 \mathrm{mg}$ iv mephenteramine, otherwise haemodynamic parameters were minimally affected (Fig I - drawn with MS Excel).

The oxygen saturation was more than 95\% (range 96-98\%) throughout the intraoperative period in all the patients. Four patients received midazolam for anxiety and 12 complained of mild itching around face, neck and upper trunk, not requiring treatment. Two patients developed pain from surgical site before the completion of surgery so they were given $5 \mathrm{ml}$ of plain bupivacaine $(0.5 \%)$ through the epidural catheter (TableII).

The first indication of block regression was observed at 60 minute after intrathecal injection with median level decreasing by two segments at 90 minutes. Post operatively, $75 \%$ $(15 / 20)$ of the patients could ambulate, but there was some minor degree of abdominal discomfort. Pruritus continued in the post operative period which was tolerable but no nausea or vomiting was observed. There were no hypotensive episodes in the post operative period (Table III-A \& III-B). Eight patients (40\%) graded the procedure as excellent while twelve (60\%) patients rated as good, none of the patients were unsatisfied with the technique.

DISCUSSION: General anaesthesia is regarded as the safest anaesthetic technique for upper gastrointestinal surgeries. But patients with major medical problems especially respiratory disease 1,2 have high risk of intra as well as post-operative complications when undergoing general anaesthesia. Regional technique ${ }^{2,3}$ have been found beneficial in situations where general anaesthesia either poses a great risk to the patient or is not feasible. A.A.J. Van Zundert et al. reported that segmental spinal anaesthesia can be used safely in patients with severe lung disease. This study shows that spinal anaesthesia ${ }^{4}$ in the lower thoracic region $\left(\mathrm{T}_{10}-\mathrm{T}_{11}\right)$ can be used to provide a segmental sub arachnoid block sufficient enough to perform cholecystectomy.

The $10^{\text {th }}$ thoracic space was chosen as it was at the center of the surgical field. The use of low dose bupivacaine and thoracic puncture allows the segmentation of the spinal block, and also minimizes the degree of thoracic motor block. The minor and transient degree of lower limb motor block may be due to minimal physical spread of local anaesthetic to the lumbosacral nerve roots. The injected opioid and local anaesthetic produced its highest concentration in the surgically relevant segmental levels.

Cardiovascular changes were minimal even though local anaesthetic spread to affect most of the spinal cord segments responsible for sympathetic out flow. It may be due to the fact that all the patients in the study group belong to ASA grade I and II, who were adequately preloaded and remained conscious throughout the procedure, thus avoiding significant central depression of circulation. The next consideration is its effect on ventilatory mechanism resulting from extensive thoracic nerve block. The ventilatory parameters ${ }^{5}$ are well preserved under this technique. It is because diaphragm which is the main inspiratory muscle is unaffected as it is innervated from the cervical level and expiration is normally a passive phenomenon at rest. 
However forceful expiration and coughing will be affected because they are generated primarily by the muscles of the anterior abdominal wall which are innervated by the thoracic nerves. In our study peripheral oxygen saturation $\left(\mathrm{SpO}_{2}\right)$ was maintained around 96-98\%.

The most dreaded complication of this technique is injury to the spinal cord since the needle is inserted above the level of termination of the spinal cord. Recent studies regarding the anatomy of thoracic spinal canal ${ }^{6}$ with MRI revealed that there is substantially more space in the posterior subarachnoid space at mid thoracic level then at lumbar and upper thoracic levels. Magnetic resonance imaging confirms that the cord and the cauda equina touch the dura mater posteriorly in the lumbar and anteriorly in the thoracic region. MRI evaluation of posterior subarachnoid space in thoracic region demonstrated mean values of $5.8 \mathrm{~mm}$ at $\mathrm{T}_{5}, 3.9 \mathrm{~mm}$ at $\mathrm{T}_{2}$ and $4.1 \mathrm{~mm}$ at $\mathrm{T}_{10}$ thoracic levels ${ }^{7}$. Thus cautious use of intrathecal injection in the thoracic segment can be another anaesthetic option without much fear of traumatizing the spinal cord. Luiz Eduardo Imbelloni et al reported segmental subarachnoid block in high risk patients undergoing colon surgery.

In our study pruritus ${ }^{8}$, cause by intrathecal fentanyl was the most common side effect seen in $60 \%(12 / 20)$ of the patients. Other side effects were both infrequent and easily managed. Patient's anxiety was another factor which interfered with our technique since they remain conscious throughout the procedure. Patients' satisfaction score was high with our technique as $75 \%(15 / 20)$ of the patients were able to ambulate pain free at the end of surgery.

Cholecystectomy under segmental thoracic epidural block in a patient with twin gestation was reported by R. Barani Selvan ${ }^{9}$ et al. Segmental subarachnoid block as an effective technique for laparoscopic cholecystectomy was reported by A.A.J. Van Zundert et al. Manoranjan $\operatorname{Kar}^{10}$ et al also reported a prospective study of 300 cases of laparoscopic cholecystectomy under spinal anaesthesia. Combined spinal epidural anaesthesia ${ }^{11}$ for laparoscopic appendectomy has been reported by Rajesh S. Mane without any complications.

CONCLUSION: In conclusion, this study shows that cholecystectomy could be successfully done under segmental thoracic spinal anaesthesia without any significant complications and may be used as an alternative technique where general anaesthesia is not feasible. The technique could be an option to expand the boundaries of regional anaesthesia in a new way. However more studies with more number of cases are required before recommending this technique for cholecystectomy.

\section{REFERENCES:}

1. van Zundert AAJ, Stultiens G, Jakimowicz J.J. ,vanden Borne BEEM, van der Ham WGJM, Wildsmith JAW. Segmental spinal anaesthesia for cholecystectomy in a patient with severe lung disease. Br J. Anaesth 2006; 96; 464-6

2. Gramatica L jr, Brasesco OE, Luna AM et al. Laparoscopic cholecystectomy performed under regional anaesthesia in a patient with chronic obstructive pulmonary disease. Surg Endosc 2002; 16: 472-5

3. Pursnani K G, Bazza Y, Calleja M, Mughal MM. Laparoscopic cholecystectomy under epidural anaesthesia in patients with chronic respiratory disease. Surg Endosc 1998; 12: 1426-8

4. A.A. J Van Zundert, G Stultiens, J.J. Jakimowicz, D. Peek, W.G.J.M. van der Ham, H.H.M. Korsten, J.A.W. Wildsmith. Laparoscopic cholecystectomy under segmental thoracic anaesthesia: a feasibility study. Br J. Anaesth 98(5): 682-6(2007) 
5. Freund FG, Bonica JJ, Ward RJ, Akamatsu TJ, Kenendy WF. Ventilatory reserve and level of motor block during high spinal and epidural anaesthesia. Anesthesiology 1967; 28: 834-7.

6. R.A. Lee, A.A.J. van Zundert, P.Breedveld, J.H.M. Wondergem, D. Peek, P.A. Wieringa. The anatomy of the thoracic spinal canal investigated with magnetic resonance imaging(MRI ). Acta Anaesthesiologica Belgica, 2007, 58: 163-67.

7. Luiz Eduardo Imbelloni, Marcelo Bianco Quirici, Jose Roberto Ferraz Filho, Jose Antonio Cordeiro, Eliana Marisa Ganem. The anatomy of the thoracic spinal canal investigated with magnetic resonance imaging. Anesth Analg 2010, 110: 1494-95.

8. Gurkan Y, Toker K. Prophyactic ondansetron reduces the incidence of intrathecal fentanyl induced pruritus. Anesth Analg 2002 Dec; 95(6): 1763-6.

9. R. Barani Selvan, David George Veliath, Parnandi Bhaskar Rao, Ramachandra, RV Ranjan. Cholecystectomy under segmental thoracic epidural block in a patient with twin gestation. Saudi Journal of Anaesthesia Vol 6, issue 1, January- March 2012; 173-75.

10. Manoranjan Kar, Jugal K. Kar, Bibhas Debnath. Experience of laparoscopic cholecystectomy under spinal anaesthesia with low pressure pneumo peritoneum- prospective study of 300 cases. Saudi journal of Gastroenterology. Volume 17, number 3, May 2011; 203-7.

11. Rajesh S. Mane, Majunath C patil, K.S. Kedareshvara, C.S. Sanikop. Combined spinal epidural anaesthesia for laparoscopic appendectomy in adults : A case series Saudi J. Anaesth. 2012 Jan-March; 6(1); 27-30

\section{Table I : Patient demographics and surgical outcome}

\begin{tabular}{|l|l|}
\hline Sex ratio (M:F) & $4: 16$ \\
\hline Age ( in years) & $41.7(\mu) ; 15.97(\mathrm{SD}) ; 19-70(\mathrm{r})$ \\
\hline Weight (in Kg) & $53.35(\mu) ; 9.22(\mathrm{SD}) ; 41-75(\mathrm{r})$ \\
\hline ASA grade I: II & $15: 5$ \\
\hline Duration of Surgery ( in minutes) & $60(\mu) ; 14.14(\mathrm{SD}) ; 45-90(\mathrm{r})$ \\
\hline Epidural Top up required & 2 \\
\hline Conversion to GA & 0 \\
\hline Patients satisfaction score(E:G:P) & $8: 12: 0$ \\
\hline & $\begin{array}{l}\mu=\text { mean, } \mathrm{r}=\text { range, } \mathrm{SD}=\sqrt{\left\{\Sigma\left(\mathrm{x}_{\mathrm{i}}-\mu\right)^{2} / \Sigma_{\mathrm{i}}\right\}} \\
\text { where } \mathrm{x}_{\mathrm{i}}=\text { observable variable, }\end{array}$ \\
\hline
\end{tabular}

Table II: Intraoperative events and medication

\begin{tabular}{|l|c|l|}
\hline Parameters & No. of patients & Intraoperative Medication provided \\
\hline Pain & 2 & Fentanyl $(50 \mu \mathrm{g})$ \\
\hline Hypotension & 5 & Mephenteramine $3 \mathrm{mg})$ \\
\hline Bradycardia & 0 & \\
\hline Anxiety & 4 & Midazolam $(2 \mathrm{mg})$ \\
\hline Pruritus & 12 & \\
\hline Nausea/ vomiting & 0 & \\
\hline $\begin{array}{l}\text { Inadequate } \\
\text { anaesthesia }\end{array}$ & 2 & Epidural bupivacaine $(0.5 \%)$ \\
\hline
\end{tabular}


Table III A: Anaesthetic Outcome (Sensory Block)

\begin{tabular}{|c|c|c|c|c|}
\hline \multirow{2}{*}{$\begin{array}{l}\text { Time } \\
\text { (in } \\
\text { minutes) }\end{array}$} & \multicolumn{2}{|c|}{ Upper level (Dermatome) } & \multicolumn{2}{|c|}{ Lower level (Dermatome) } \\
\hline & $\begin{array}{l}\text { Distribution(no of } \\
\text { pt) }\end{array}$ & $\begin{array}{l}\text { Median(rang } \\
\text { e) }\end{array}$ & $\begin{array}{l}\text { Distribution(no of pt) } \\
\text { L1:L2:L3:L4:L5 }\end{array}$ & $\begin{array}{l}\text { Median(rang } \\
\text { e) }\end{array}$ \\
\hline 15 & 5:12:3 (T3:T4:T5) & $\mathrm{T}_{4}\left(\mathrm{~T}_{3}-\mathrm{T}_{5}\right)$ & $2: 2: 12: 2: 2$ & $\mathrm{~L}_{3}\left(\mathrm{~L}_{1}-\mathrm{L}_{5}\right)$ \\
\hline 30 & 5:12:3 (T3:T4:T5) & $\mathrm{T}_{4}\left(\mathrm{~T}_{3}-\mathrm{T}_{5}\right)$ & $2: 2: 12: 2: 2$ & $\mathrm{~L}_{3}\left(\mathrm{~L}_{1}-\mathrm{L}_{5}\right)$ \\
\hline 45 & 3:10:7 (T3:T4:T5) & $\mathrm{T}_{4}\left(\mathrm{~T}_{3}-\mathrm{T}_{5}\right)$ & $2: 2: 12: 2: 2$ & $\mathrm{~L}_{3}\left(\mathrm{~L}_{1}-\mathrm{L}_{5}\right)$ \\
\hline 60 & 7:10:3 (T4:T5:T6) & $\mathrm{T}_{5}\left(\mathrm{~T}_{4}-\mathrm{T}_{6}\right)$ & $2: 10: 4: 2: 2$ & $\mathrm{~L}_{2}\left(\mathrm{~L}_{1}-\mathrm{L}_{5}\right)$ \\
\hline 75 & 4:8:8 (T4:T5:T6) & $\mathrm{T}_{5}\left(\mathrm{~T}_{4}-\mathrm{T}_{6}\right)$ & $2: 10: 4: 2: 2$ & $\mathrm{~L}_{2}\left(\mathrm{~L}_{1}-\mathrm{L}_{5}\right)$ \\
\hline 90 & 4:10:6 (T5:T6:T7) & $\mathrm{T}_{6}\left(\mathrm{~T}_{5}-\mathrm{T}_{7}\right)$ & $12: 15: 2: 2: 1$ & $\mathrm{~L}_{1}\left(\mathrm{~T}_{12}-\mathrm{L} 4\right)$ \\
\hline
\end{tabular}

Table III B: Anaesthetic Outcome (Motor Block)

\begin{tabular}{|l|c|c|c|c|}
\hline & No. of patients with Bromage Grade \\
\hline Bromage Grade & 0 & 1 & 2 & 3 \\
\hline Before Surgery & 14 & 3 & 3 & 0 \\
\hline After Surgery & 15 & 3 & 2 & 0 \\
\hline No. of patients able to ambulate at the end of surgery $=15 / 20$ \\
\hline
\end{tabular}

Figure I: Haemodynamics

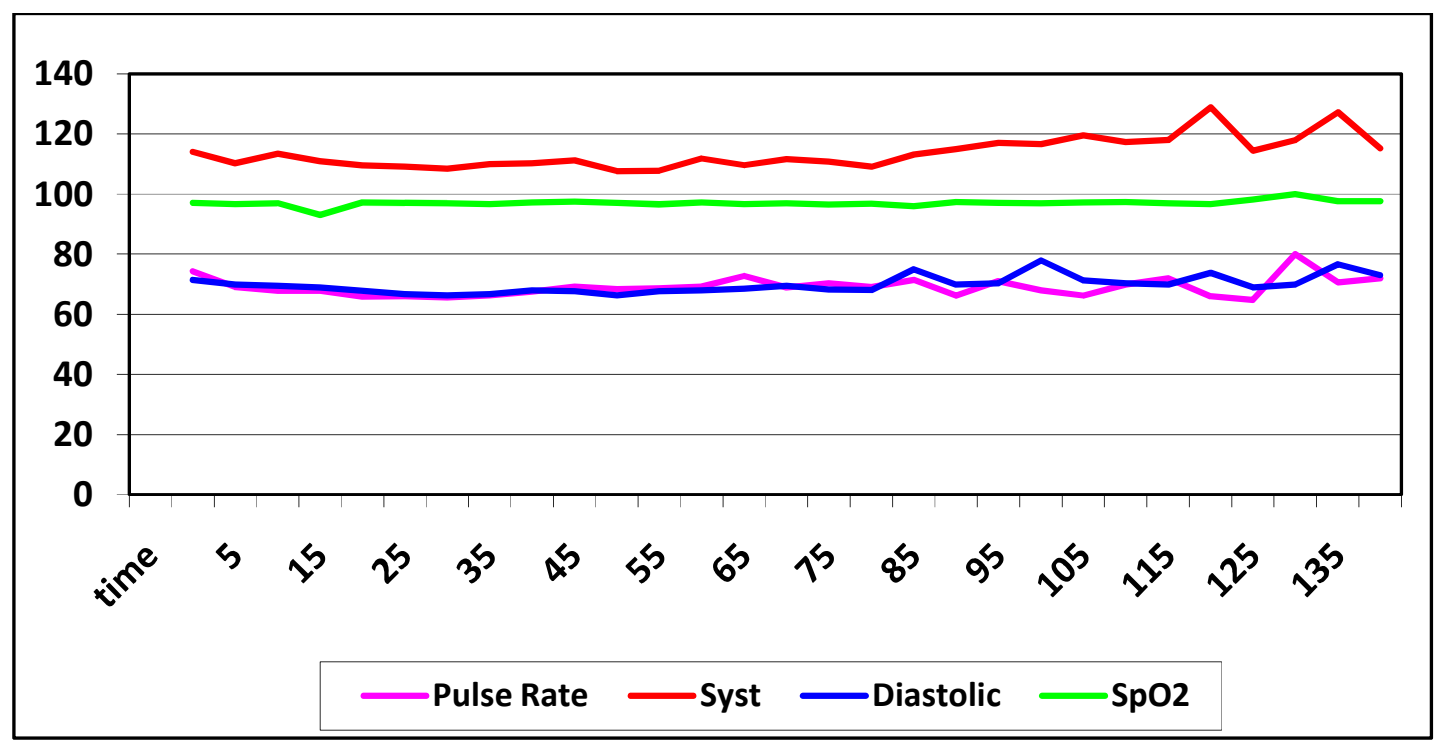

